\title{
The Young and the Restless
}

\author{
"Age is an issue of mind over matter. If you don't mind, it doesn't matter." —Mark Twain
}

$\mathbf{T}^{\mathrm{h}}$ he issue of aging academics in times of budgetary constraints has stirred vigorous debate. Many older professors continue to be productive researchers and inspiring teachers with plenty of wind in their sails. However, some say the abundance of older professors is clogging an already narrow bottleneck, making it harder for young faculty members to bring fresh ideas, challenges and technologies into labs and lecture halls. Others worry that the perseverance of older professors is crowding the young out of tenure positions altogether.

A wave of academics whose careers began in the 1950s and 1960s has changed current research environments by working well into their $70 \mathrm{~s}$ and occasionally $80 \mathrm{~s}$. The baby boomers are also approaching retirement, but as a result of improvements in health and productive longevity, and in part owing to social expectations, they are now shunning the golf courses and campervans of the retirement world and choosing to remain professionally active. In 2006, almost $10 \%$ of tenured professors in Harvard's Faculty of Arts and Sciences were 70 or older, compared with none in 1992. Funding statistics also reflect this situation. Investigators over age 55 received $22.7 \%$ of US National Institutes of Health research awards in 2003, up from just 9.7\% 20 years earlier. Other countries have also seen a rise in the percentage of older professors, particularly Australia and Canada, who, like the United States, abolished mandatory retirement due to acts introduced in the 1990s prohibiting age discrimination in employment.

At the other end of the spectrum, the scientific environment for junior scientists is changing dramatically. In recent years the number of people graduating with $\mathrm{PhDs}$ has increased substantially. This has expanded the pool of young academics competing for the same funding and for the limited, often static number of tenured positions. Over the past two decades, the percentage of scientists in the United States holding tenured or tenure-track appointments 5-6 years after completing their PhDs fell from around 34\% to just 14\%. The average age at which scientists get their first independent $\mathrm{NIH}$ research grant has risen from 37 to 42 in the last 25 years. In Australia, for a 2007 round of Australian Research Council grants, those over the age of 50 made up almost 50\% of all successful applicants, whereas those in the 30-34 bracket just $6 \%$. In Germany, the average age at which scientists receive their first grants from the German Research Council (DFG) is close to 41.

Only a small minority of today's $\mathrm{PhD}$ graduates can realistically expect long-term careers in university research. This bottom-heavy system, which is worsened by the slower pace of retirements in the sciences, is resulting in young scientists spending more years in postdoctoral positions, or sometimes not pursuing academic research at all. A 'catch-22' also emerges whereby the increasingly late start allows for only 20 or so years of independent research in a scientist's career if retirement is expected at the age of 60 or 65 .
It would be disingenuous to join the clamor for forcing the 'fuddyduddies' to move on by means of a return to the era of mandatory retirement. Forcing people to retire carries its own set of problems. In countries such as Japan, China and Germany where retirement ages are still defined, many older researchers in their prime have met this fate. Some have ended their careers prematurely, while others have moved on to more welcoming environments in which many have made their biggest discoveries. Japan, however, is gradually increasing retirement age from 60 to 65 between 2006 and 2013, and Singapore has increased retirement to 62 with academics now being exempt. In China, where mandatory retirement was placing a strain on the ability of expanding universities to maintain teaching staff numbers, adequate retirement age has been increased and older colleagues supported to continue research outside official faculty positions.

What then is the solution? Both young and old scientists need to be nurtured. To achieve this balance, which is essential in maintaining scientific vitality, some universities in Canada and the United States have pioneered voluntary retirement schemes by offering senior academics postretirement appointments in 'Senior Scholar Centers' or 'Retiree Centers'. Academics past their formal years of service are given office space, access to all research facilities and continued links with research departments, colleagues and public lectures, but they vacate their faculty position for someone else. Their research life remains active so that 'retirement' from faculty is far from the end professionally. At the Walter and Elisa Hall Institute (WEHI) in Melbourne, where the median age of Level E Senior Principal Research Fellows (professors) is 62 (the oldest is 78 and the youngest 43), reappointment every five years is based on continued performance without consideration of age. Older scientists, however, are encouraged to reduce their lab size to provide opportunities for younger scientists' groups to expand.

In this era of aging populations and changing scientific environments, university and grant administrators should design programs that facilitate the support of researchers at all stages of their careers. Policies should be nondiscriminatory, provide flexible working arrangements and recognize the value of the accumulated knowledge, experience and renown that senior scientists bring their institutions, and they should continue to foster these scientists' participation. However, this should be combined with formal performance assessment of publication output, grants and teaching, and with the conscious creation of space for youth. One such mechanism for supporting young faculty is to create funding pools that are designated solely for first-time grant applicants. These actions will allow free flow and support of the next generation while enabling the older generation to thrive for the benefit of the biomedical community. 